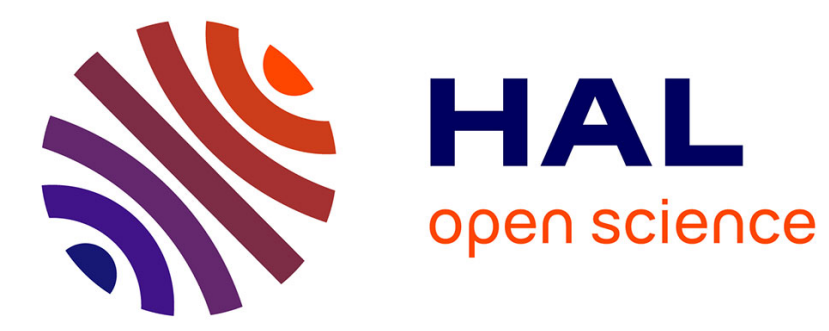

\title{
Dynamic tensile fracture phenomena at wave propagation in ceramic bars
}

\author{
J. Najar
}

\section{To cite this version:}

J. Najar. Dynamic tensile fracture phenomena at wave propagation in ceramic bars. Journal de Physique IV Proceedings, 1994, 04 (C8), pp.C8-647-C8-652. 10.1051/jp4:1994898 . jpa-00253459

\section{HAL Id: jpa-00253459 https://hal.science/jpa-00253459}

Submitted on 1 Jan 1994

HAL is a multi-disciplinary open access archive for the deposit and dissemination of scientific research documents, whether they are published or not. The documents may come from teaching and research institutions in France or abroad, or from public or private research centers.
L'archive ouverte pluridisciplinaire HAL, est destinée au dépôt et à la diffusion de documents scientifiques de niveau recherche, publiés ou non, émanant des établissements d'enseignement et de recherche français ou étrangers, des laboratoires publics ou privés. 


\section{Dynamic tensile fracture phenomena at wave propagation in ceramic bars}

J. Najar

Lehrstuhl A für Mechanik, Technische Universität, Arcisstr. 21, 80290 Muenchen, Germany

Résumé: Un analyse ici des expériences de clivage dynamique de céramiques sous tension uniaxiale à température ambiante et élevée afin de questionner l'application du schéma de l'onde unidimensionelle dans le cadre de la théorie de l'endommagement des matériaux élastiques fragiles. Les effets de clivages multiples sont pris en compte dans le calcul de l'énergie de rupture.

Abstract: Spalling experiments with alumina ceramics in the uniaxial state of stress at room and elevated temperatures are discussed here from the point of view of the applicability of the one-dimensional wave pattern in the framework of the continuum damage mechanics of brittle elastic materials. Effects of strength and multiple spalling are analysed on the basis of the fracture energy measurements.

\section{Introduction}

The dominant mode of fracture in ceramics under static loads is tensile. In the dynamic case of transient loading at uniaxial strain, e.g. plate impact experiments at strain rates of $10^{4} \mathrm{~s}^{-1}$ and more, [1], the tensile mode of fracture is related to spalling effects attributed to high excitations of very short pulse components, interacting with distributed sources of microdamage with eigen-frequencies of some 25-50 M Hz, [2], [3]. On the other hand, at uniaxial stress dynamics, e.g. in experiments with thin bars, [4], where only strain rates of up to $10^{3} \mathrm{~s}^{-1}$ can be achieved, the tensile mode of fracture remains prevailing in ceramics, although its mechanisms cannot be identified with dynamic source excitations, and need to be investigated yet. Having in mind applications of ceramics at dynamic and thermal exposures, attention should be paid to conducting the latter kind of experiments at various temperatures, and to their analysis. An attempt to formulate an adequate mechanical model for spalling at uniaxial stress in elevated temperatures seems to be worth of consideration.

A brief account of extensive spalling experiments with alumina ceramics performed in uniaxial stress at room and elevated temperatures is given in the present paper. The results for dynamic tensile strength of bar specimens and for specific fracture energy in spalling are discussed. The applicability of the continuum damage model, [5], to the description of the measured parameters within the framework of the one-dimensional wave pattern, as applied in the evaluation of the tests, is discussed.

\section{Experimental arrangement}

The split Hopkinson pressure bar (SHPB) apparatus cannot be properly applied for dynamic tensile experiments with ceramics: failure develops in this brittle material within one wave passage, provided the pulse amplitude is high enough, while the SHPB evaluation procedure is based on the multiple reflection assumption. Complicated shapes of specimens' grips, needed in most tensile SHPB versions, s. [4], cause here additional scatter and high costs. 
On the other hand, most sledgehammer-type tensile devices, s. [6], demand instrumented specimens and involve complicated wave patterns, necessitating in extensive numerical calculations in the evaluation of the results. Testing at elevated temperatures is here practically impossible, due to the limitations on strain measurements in hot fields above $1000^{\circ} \mathrm{C}$. When large numbers of specimens need to be tested because of their natural scatter of mechanical properties, the cost of long series presents another handicap.

Therefore, a special testing set-up is needed for tensile dynamic fracture of slender bars. Specific properties of ceramics, in particular: its relatively low fracture toughness, very short fracture delay time, and high compressive - to - tensile strength ratio, have allowed to build the apparatus based on the spalling principle, and to develop an efficient and simple evaluation procedure, [7].

The set-up combines the SHPB principles of pulse initiation and its measurement with the tensile dynamic loading arising in result of the reflection of the compressive stress wave from specimen's free end, typical for spalling experiments. The slenderness ratio of 20 and more, and a carefully selected pulse profile result in the spall developing sufficiently far away from the reflection point to secure uniaxial stress, Fig. 1.

For experiments at elevated temperatures, the specimen can be placed in an open-ends furnace lined along the axis of the set-up. In this case, an extension piece of the same material as the specimen is positioned between it and the transmitter bar, in order to bridge over the thermally inhomogeneous field at the opening of the furnace.

The compressive pulse induced in the transmitter bar by projectile impact as it travels along gets registered at gauge stations and stored. The same happens to the reflected pulse resulting from the difference of the effective impedances between the transmitter bar and the specimen. The compressive pulse, $\sigma_{t}$, transmitted into the specimen propagates here without causing material damage. Upon its arrival at the free end it gets reflected as a tensile pulse and superposed upon the still arriving tail, [8]. The resulting stress distribution leads to tensile stresses increasing with the distance from the free end and fast growing in time, Fig. 2.

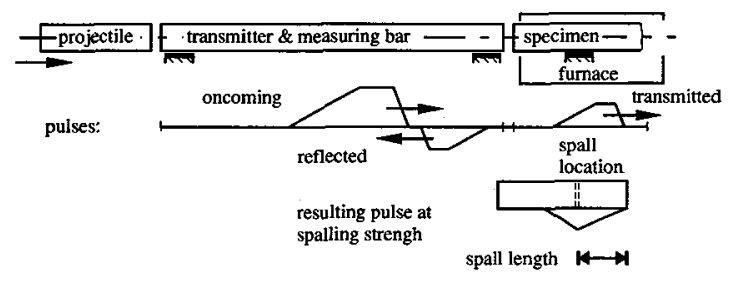

Figure 1: Experimental arrangement

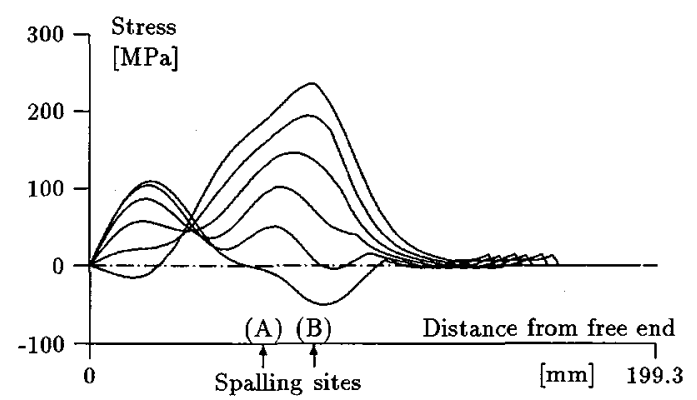

Figure 2: Resulting transient pulses in the specimen, in a time-step sequence $0,5 \mu \mathrm{s}$

Wherever the peak value of the resulting stress distribution reaches the level of the tensile strength $\sigma_{f}$ of the material, spalling occurs. The part of the pulse and the momentum trapped in the fragment cause in most cases secondary in-flight fractures based on the same mechanism, provided sufficient $\sigma_{t^{-}}$ pulse amplitude. The knowledge of the site of the primary spall, when confronted with the computerevaluated resulting terisile stress evolution in the specimen, allows for determination of its spall strength.

Problems of adequate modelling, evaluation procedures for stress distribution, distinguishing of primary and secondary spalling sites, etc. needed to be investigated here. The evaluation procedure for stresses and determination of the spalling instance has been given in [9]. Attention has been paid 
Table 1: Dynamic tensile strength of alumina rods at room temperature

\begin{tabular}{cccccl}
\hline $\begin{array}{c}\text { Series } \\
\text { no. }\end{array}$ & $\begin{array}{c}\text { no. of } \\
\text { specim. }\end{array}$ & $\begin{array}{c}\text { dia. / length } \\
\mathrm{mm}\end{array}$ & $\begin{array}{c}\text { mean strength } \\
\mathrm{MPa}\end{array}$ & $\begin{array}{c}\text { scatter } \\
\%\end{array}$ & $\begin{array}{l}\text { cross-sect. } \\
\text { type }\end{array}$ \\
\hline $\mathbf{1}$ & 12 & $4 / 200$ & 319 & 9.7 & full \\
2 & 13 & $8 / 200$ & 274 & 12.0 & full \\
3 & 11 & $8 / 200$ & 273 & 9.5 & full \\
4 & 9 & $8 / 200$ & 276 & 13.0 & full \\
5 & 9 & $12 / 200$ & 207 & 23.7 & full \\
6 & 9 & $12 / 330$ & 209 & 17.2 & full \\
7 & 11 & $8 / 200$ & 162 & 17.9 & 2 holes \\
8 & 13 & $8.5 / 200$ & 209 & 18.2 & 4 holes \\
9 & 12 & $8 / 200$ & 184 & 16.8 & 8 holes \\
\hline
\end{tabular}

to distinguishing geometrical from physical dispersion, [10], to account for the effects of multiple spalling and to single out primary fractures, [11], allowing for proper assessment of the size-effect in strength, [12], and the temperature effects, [13].

\section{Experimental results on spalling strength}

Some observations regarding spalling strength tests with monolithic alumina bars at room temperature are presented in this chapter. Tab. 1 shows the resulting data for 9 test series, altogether 99 specimens, for details s. [12]. Observe first that the mean tensile strength $\sigma_{f}$ of full bars drops linearly with the increase of the cross-section area $A$ of the specimen, Fig. 3 . Also, with $A$ grows systematically the scatter of the strength. These size-effects can be well interpreted within the weakest link concept of the failure probability treatment, as commonly applied to static experiments with ceramics, [14]. Also the level of the measured stress at spall $\sigma_{f}$ corresponds to the strength values measured in static experiments, e.g. bending strength, [15].

This doesn't mean, however, that the moderately high strain rates in the range of 200-500 $\mathrm{s}^{\mathbf{- 1}}$, as observed in the tensile loading phase at the site of fracture, comp. Fig. 1, have no effect on the failure mechanism in spalling at uniaxial stress. We have reasons to believe that it is only the quasi-static mode of failure initiation, where weakest link hypothesis is still applicable. The propagation of the spall thus initiated is, on the other hand, not compatible with the static fracture concept, and leaves its imprint on the fracture energy, s. ch. 4.

The influence of the cross-section geometry on the strength of rods can not be directly related to the area $A$ alone, as the tests with axially perforated rods (holes 0.8 to $1.6 \mathrm{~mm}$ diameter) indicate, s. series 7-9, Tab. 1. The drop in the mean strength, as compared with full rods of the same size, s. series $2-4$, and the increase of its scatter indicate rather a drop in the homogeneity of the samples due to manufacturing, and confirm the applicability of the weakest link hypothesis.

Similar analysis, although more complicated by taking into account temperature inhomogeneities in the wave path, as well as the temperature dependence of the Young modulus and the material density, applies to the preliminary tests at temperatures up to $1000 C^{\circ},[13]$, where similar scatter characteristics as those at room temperature have been found.

\section{Experimental results on fracture energy}

Multiple fractures in the experiments presented in ch. 3 show a seemingly irregular pattern of distribution, the distances between them ranging between $12 \mathrm{~mm}$ and over $50 \mathrm{~mm}$, in average around 20 $m m$, independently of the diameter of the specimen.

The data extracted from such tests can be used also for the determination of the fracture energy $W_{f}$ in spalling. With this goal, the difference between the energy $W_{t}$, carried by the $\sigma_{t}$-pulse into the 
specimen, and the sum of the kinetic energies $W_{k}^{n}$ and energies of vibrations $W_{v}^{n}$ of all $n$ fragments, $W_{f}=W_{t}-\sum_{n}\left(W_{k}^{n}+W_{v}^{n}\right)$ needs to be evaluated. Thanks to the favourable test configuration, friction losses are negligible and independent of the pulse amplitude, and therefore could be excluded from the energy balance.

By performing spalling tests with different pulses $\sigma_{t}$, and obtaining thus different numbers of fragments, one can find the dependence of the global fracture energy $W_{f}$ of the overall fracture surface area $A_{f}=\sum_{n} A_{f}^{n}$. Its determination has been complicated in many cases by spall branching and further fracturization, demanding a thorough account of all (up to 70) fragments.

For the determination of the kinetic energy $W_{k}^{n}$ of the fragments, continuous shadow photography within a period of some $6 \mathrm{~ms}$, triggered $\sim 10 \mathrm{~ms}$ after the beginning of spalling, in order to distinguish single fragments, has been performed with a photographic Zeiss device containing a fast revolving drum. The evaluated value $W_{k}=\sum_{n} W_{k}^{n}$ of the global kinetic energy shortly after fragmentation has been found in all tests to be substantially higher than the mean translatoric kinetic energy $\tilde{W}_{k}$ of the specimen shortly before spalling, numerically determined on the basis of the $\sigma_{t}$-pulse, Fig. 4.

This means that the initial potential energy $W_{t}-\tilde{W}_{k}$, stored in the specimen just before the spall, not only supplied the fracture energy $W_{f}$, but has also contributed to the increase of the global kinetic energy, while another part, $W_{v}=\sum_{n} W_{v}^{n}$, has been trapped in the vibrations of the flying fragments. It can be shown analytically that the values of $W_{v}^{n}$ converge fast to the energy of axial vibrations with their eigen-frequencies at amplitudes corresponding to given fractions of the tensile strength $\sigma_{f}$, determined by the fragments' geometry. An increase in the number $n$ of spalls has therefore no substantial influence on the value of $W_{v}$.

The tests have shown, s. Fig. 4 as an example, that within a certain scatter all energy components in eqn. (1) change linearly with the fragmentation area $A_{f}$, for a given geometry of the specimen. By extrapolating the straight line $\left(W_{t}-W_{k}\right)$ to $A_{f}=0$ one obtains on the strength of the above arguments the value of $W_{v}$, which is assumed to be constant within the range of $A_{f}$ for a given series. The value $W_{f}$, as calculated from the energy balance, shows a linear dependence of $A_{f}$, while its incline characterizes the specific fracture energy $w_{f}=W_{f} / A_{f}$.

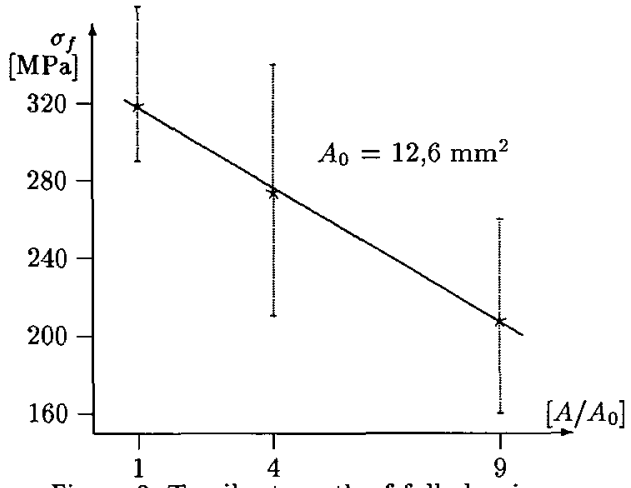

Figure 3: Tensile strength of full alumina rods vs. cross-section area

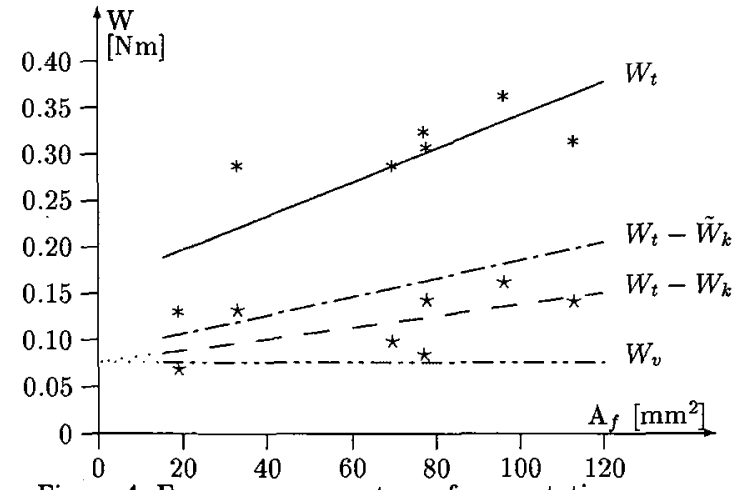

Figure 4: Energy components vs. fragmentation area, Alumina full rods $4 \mathrm{~mm}$ dia., $200 \mathrm{~mm}$ length

The comparison of the results of tests with alumina bars of different geometries is given in Table 2. Specific fracture energy appears to be, within some scatter, not so much dependent of the geometry, but rather related to the respective bar's density. The mean value of $w_{f}$ for the first 5 test series is $594 \mathrm{~N} / \mathrm{m}$, with $8 \%$ scatter, while the density changes are $3 \%$. For the axially perforated specimens (the last 3 series), the drop in $w_{f}$ with the decrease of the density is probably indicative to dropping material's coherence due to the differences in fabrication technology of the ceramic bars. 
Table 2: Specific fracture energy at multiple spalling

\begin{tabular}{cccccc}
\hline $\begin{array}{c}\text { Dia. / length } \\
m m\end{array}$ & $\begin{array}{c}\text { cross-sect. } \\
\text { type }\end{array}$ & $\begin{array}{c}\text { density } \\
\mathrm{g} / \mathrm{cm}^{3}\end{array}$ & $\begin{array}{c}\text { fragm. area } \\
\mathrm{mm}^{2}\end{array}$ & $\begin{array}{c}\text { no. } \\
\text { tests }\end{array}$ & $\begin{array}{c}\text { specif. fract. } \\
\text { energy, } \mathrm{N} / \mathrm{m}\end{array}$ \\
\hline $4 / 200$ & full & 3.90 & $18-113$ & 8 & 620 \\
$8 / 200$ & full & 3.92 & $88-492$ & 8 & 660 \\
$12 / 330$ & full & 3.91 & $304-1135$ & 9 & 570 \\
$8 / 200$ & 2 holes & 3.79 & $59-392$ & 8 & 570 \\
$8.5 / 200$ & 4 holes & 3.78 & $72-455$ & 8 & 550 \\
$8 / 200$ & 8 holes & 3.38 & $42-326$ & 8 & 380 \\
\hline
\end{tabular}

\section{Spalling effects in the continuum damage interpretation}

Consider the results of the ch. 4 in the framework of elasto-static fracture, as the strength investigation of ch. 3 seems to indicate. Literature data on fracture toughness in Mode I yield for alumina $K_{I c}$ up to $5 \mathrm{MPa} \sqrt{\mathrm{m}}$, [14], i.e. critical energy release rates $G_{I c}=K_{I c}^{2} / E$ in the range of under $60 \mathrm{~N} / \mathrm{m}$. Resistance curves for stable crack propagation in alumina, [15], show an increase in the resistance energy up to $\sim 90 \mathrm{~N} / \mathrm{m}$ for 4-point beams and $\sim 120 \mathrm{~N} / \mathrm{m}$ for CT-specimen configuration. Thus, the values of $w_{f}$ presented in Tab. 2, when compared with these parameters, indicate at a different mechanism of fracture at spalling in uniaxial stress, consuming more energy than single crack propagation in tension by an order of magnitude.

From the micro-mechanical point of view the mechanism seems to be quite clear: fracture initiation begins at the largest microcrack, s. weakest link hypotheses, as an almost instant response to the global tensile stress $\sigma_{f}$, due to the very short delay time in ceramics. Although the Mode I does not need to control the initiation, as long as microcracks are of subcritical size, i.e. here $\ll 2\left(K_{I c} / \sigma_{f}\right)^{2} / \pi \simeq$ $0.1 \mathrm{~mm}$, it takes over very soon after the crack starts to propagate. Since in most multiple spall experiments the amplitude of the $\sigma_{t}$-pulse substantially exceeds $\sigma_{f}$, the propagating crack is overrun by an increasing stress in the resultant tensile wave, s. Fig. 2. This interference may take place anytime, until the crack has completed crossing the bar, i.e. within $\sim 1 \mu \mathrm{s}$. Still, as Fig. 2 illustrates, this may mean a stress overshot of as much as 60 to $100 \mathrm{MPa}$ above some 270 to $320 \mathrm{MPa}$.

The overstress activates, on one hand, many smaller mikrocracks both ahead of the running crack, in the plane of the developing spall, and in some vicinity of the spall plane, depending on the resultant stress gradient; on the other hand, it causes a higher energy release rate $G_{I} \sim \sigma_{t}^{2}$, flowing into the tip of the running major crack. The result is its forced branching, which depends on the relation between the evolution of the overstress wave profile and the parallel rise of the activated minor cracks. Unlike the static tensile fracture, where the largest crack dominates the field of the given critical stress, in the dynamic case the chance for a shadow effect, and thus for a single crack fracture mechanism, is due to the overstress rather low.

The interaction of the main spalling crack with its activated environment causes a complicated dynamic three-dimensional pattern, where the static Mode I notions are not applicable anymore. The energy intake in this pattern can be hardly predicted at the present, but obviously contributes to the high fracture losses.

It is hard to assess, on the other hand, to which extent a possible underestimation of the fracture area $A_{f}$ took place in the tests, due to many branchings of the spalls and strong fragmentations in their vicinity. Still, the observed inequality $w_{f} \gg G_{I c}$ needs more than just these explanations. The presented tests show namely a striking consistence, almost incompatible with the more or less chaotic picture given above, depending essentially on random distributions of the microcracks and on non-repeatable stress patterns.

The continuum damage approach, as applied to tensile fracture in elastic-brittle materials, [5], may 
present at least a convenient phenomenological tool for the description of the effect. The thermomechanically based model for moderate strain rates assumes the dominance of tensile failure over that in compression, which results in the following description of the uniaxial variable loading:

$$
\sigma=E \varepsilon_{e f f}, \quad \varepsilon_{e f f}=\varepsilon-\varepsilon_{r}
$$

where the residual strain $\varepsilon_{r}$ develops only in tensile loading, together with damage $D$, according to the rate rules

$$
d \varepsilon_{r}=D d \varepsilon+\varepsilon_{e f f} d D, \quad d D=\frac{E}{W^{*}} D \varepsilon_{e f f} d \varepsilon, \quad \varepsilon_{e f f}>0, \quad d \varepsilon>0
$$

In unloading $(d \varepsilon \leq 0)$, as well as in compression $\left(\varepsilon_{e f f}<0\right)$, there is neither damage evolution nor change of the residual strain possible.

For initial conditions: $D=D_{0}$ at $\varepsilon=0$, where $D_{0}$ is the amount of initial damage, while $E$ denotes the Young modulus of the undamaged material and $W^{*}$ represents the energy absorption capacity of the material, one obtains a kinematically well - posed problem of the response to a transient dynamic loading. The spall limit $\sigma_{f}$ can be found as the carrying capacity of the material, and thus calculated in a step-by-step procedure, when model parameters $E, D_{0}$ and $W^{*}$ are known, [5]. An estimate based on the present results on spalling strength, ch. 3 , yields values of $W^{*} \simeq 60 \mathrm{kN} / \mathrm{m}^{2}$ and $D_{0} \simeq$ 0.01 for $E=390$ GPa.

Applying these parameters to the specific energy results, ch. 4, this would mean a dependence of the initial damage of the bars $D_{0}$ of their diameter, reflecting the size effect, ch. 3 . Another relation between the parameters $W^{*}$ and $w_{f}$, in the form $w_{f}=W^{*} \delta$, enters here, $\delta$ corresponding to an equivalent length of the damage zone in the vicinity of a spall, which depends on the stress profile in the tests and its evolution in multiple spalling within the uniaxial treatment. For the above data on $w_{f}$ and $W^{*}$ one obtains $\delta \simeq 10 \mathrm{~mm}$. The observed pattern of distributions of spalling sites, s. ch. 3 , fits well by its magnitude with the value of $\delta$, needs however further identification by relating to the pulses registered in the experiments. The model allows for its extension into the range of elevated temparatures, by establishing the dependendence $W^{*}(T)$ from the corresponding strength tests.

\section{ACKNOWLEDGEMENTS}

The work presented here has been performed in relation with the DFG project $\mathrm{Na}-218$ on dynamic testing of high performance ceramics. Dr. S. Bierwirth has supervised the construction of the experimental arrangement and conducted the tests. The financial support of the German Research Community and Dr. S. Bierwirth's cooperation are hereby gratefully acknowledged.

\section{REFERENCES}

[1] Rajendran, A.M., Cook, W., Rep, AFATL-TR-88-143 (1988), Univ. Dayton Res. Inst..

[2] Bellendir E.N., Belyaev V.V. and Naimark O.B., Letters J. Techn. Phys. 15, 13, (1989) 90-93.

[3] Seaman L., Curran D.R. and Shockey D.A., J. Appl. Phys., 47 (1976) 4814-4826.

[4] Nicholas T., Exp. Mech. 21 (1981) 177-185.

[5] Najar, J., Int. J. Damage Mechanics 4 (1994), to appear.

[6] Kussmaul K., Demler T. and Klenk A., Materials at High Strain Rates, Inst. Phys. Conf., Ser. No. 102, Sess. 4, Oxford 1989 (IOP Publ. 1989), 157-164.

[7] Bierwirth S. and Najar J., 13. GESA-Symp., Bremen 1990, (VDI, 1990), 403-421.

[8] Kolsky, H., Stress waves in solids (Oxford Univ. Press, 1953).

[9] Najar J., Proc. 8 Int. Conf. Fract., Kiev, 1993, in print.

[10] Bierwirth S. and Najar J., 23. DVM-AK Bruchvorgaenge, Berlin 1991 (DVM, 1991) 423-432.

[11] Najar J. and Bierwirth S., 24. DVM-AK Bruchvorgaenge, Aachen 1992 (DVM, 1992) 439-451.

[12] Bierwirth S., Dissertation, TU Muenchen (1993)

[13] Bierwirth S. and Najar J., 25. DVM-AK Bruchvorgaenge, Karlsruhe 1993, (DVM, 1993) 483-493.

[14] Munz D. and Fett T., Mechanisches Verhalten keramischer Werkstoffe (Springer, 1989)

[15] Nickel, H. and Steinbrech, R.W. (eds.), Mikrobruch in $\mathrm{Al}_{2} \mathrm{O}_{3}$-Keramik, DFG, Juelich, 1990 